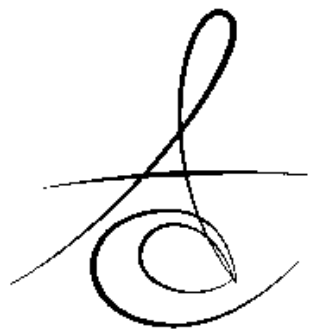

\title{
DENTİN HASSASİYETİNİN TANISI, ETYOLOJİSİ VE GÜNCEL TEDAVİ YAKLAŞIMLARI: DERLEME
}

\section{DIAGNOSIS, ETIOLOGY AND CURRENT MANAGEMENT OF DENTIN HYPERSENSITIVITY: A LITERATURE REVIEW}

\author{
Öğr. Gör. Dr. Dt. Samet TOSUN*
}

Yrd. Doç. Dr. A. Semih özsEvi̇k**

Makale Kodu/Article code: 2116

Makale Gönderilme tarihi: 05.02 .2015

Kabul Tarihi: 13.05.2015

\section{ÖZET}

Günümüzde giderek artan bir sorun olan dentin hassasiyeti dişlerin ağız ortamına açılmış dentin yüzeylerinde herhangi bir dental defekt veya başka bir patoloji olmaksızın, kimyasal, dokunma ya da ozmotik uyaranlar sonucu kısa süreli, keskin bir ağrı ile karakterize klinik bir durumdur. Çok sayıda hasta ISI, dokunma, tatlı ya da ekşi gibi uyarılara karşı hassasiyet duyduklarında ağrılarına çare bulmak amacıyla diş hekimlerine başvurmaktadırlar. Genel olarak dentin hassasiyetinin tedavisinde hassasiyet giderici ajanların etkisini göstermesinde kabul gören iki mekanizma bulunmaktadır. Dentin tübüllerinin tıkanarak SIVı hareketinin bloklanması ve duyu sinirlerinin duyarılığının azaltılarak uyarana karşı gelişen cevabın değiştirilmesi veya azaltılmasıdır. Bu amaçlara uygun olarak farklı fiziksel ve kimyasal ajanların kullanımı ve farklı tedavi stratejileri gündeme gelmektedir. Bu derlemede, dentin hassasiyetinin etyolojisi ve tedavi yöntemlerindeki güncel yaklaşımlar hakkında bilgi verilmesi amaçlanmaktadır.

Anahtar Kelimeler Dentin hassasiyeti, etyoloji, desensitize edici ajanlar, lazer

\section{GİRIŞ}

Günümüzde çok sayıda hasta ıSı, dokunma, tatlı ya da ekşi gibi uyaranlara karşı hassasiyet duyduklarında, ağrılarına çare bulmak amacıyla diş hekimlerine başvurmaktadırlar. Dentin hassasiyeti dişlerin ağız ortamına açılmış dentin yüzeylerinde başka bir defekt ya da hastalık olmaksızın, kimyasal, dokunma ya da ozmotik uyarılara karşı verilen yanıt olup kısa süreli, keskin bir ağrı ile karakterize klinik bir durumdur. ${ }^{1}$

\section{ABSTRACT}

Dentin hypersensitivity is a clinical condition characterized by short, sharp pain arising from exposed dentin in response to stimuli-typically thermal, evaporative, tactile, osmotic, or chemical which is a problem in today's increasingly, cannot be attributed to any other dental defect or pathology. Patients having sensitivity of heat, touch, sweet or sour prefer to go to a dentist to get over the pain. Generally, there are two mechanisms which are accepted as the corrector of sensitivity in dentin hypersensitivity treatment: blockage of fluid movement due to the congestion of dentinal tubules and modification or reduction of the response to the stimulus by decreasing sensitivity of the sensory nerves. For this purpose, utilisation of different physical and chemical agents as well as other treatment strategies have been investigated. In this review, current approaches in dentin hypersensitivity is aimed to give information about the and treatment methods.

Key words: Dentin hypersensitivity, etiology, desensitizing agents, laser

Genelde 20-50 yaşlarında görülse de erken ergenlikten $70^{\prime}$ li yaşlara kadar dağıım göstermektedir. ${ }^{2}$ Dentin hassasiyetine yönelik olarak yapılan çalışmalarda, farklı toplumlarda \%4-74 arasında değişik oranlarda dentin hassasiyetinin görüldüğü saptanmıştır. $^{3}$ Dentin hassasiyeti genç yetişkinlerde en yüksek oranda prevalansa sahip iken artan yaşla birlikte bu prevalans düşmektedir. ${ }^{4,5}$

\section{Dentin Hassasiyetinin Etyolojisi}

Dentin hassasiyetinin etyolojisinde farklı etkenler rol oynamaktadır. Esas olarak diş eti çekilmesi, mine veya sementin kaybı servikal dentinin veya kök

\footnotetext{
* Gaziantep Üniversitesi Diş Hekimliği Fakültesi Endodonti Anabilim Dalı

** Gaziantep Üniversitesi Diş Hekimliği Fakültesi Restoratif Diş Tedavisi Anabilim Dalı
} 
dentinin yada dentin tübüllerinin ağız ortamına açılmasında etkilidir. ${ }^{6}$ Ayrıca gelişimsel olarak normalde anatomik kronun üzerini kaplayan mine ile kök yüzeyini kaplayan sementin servikal bölgedeki birleşim şekilleri incelendiğinde \%30 vakada uç uca geldiği, \%60 vakada sementin minenin üzerinde sonlandığı ancak \%10'luk bir vakada ise mine ile sementin birleşmediği ve dentin yüzeylerinin ağız ortamına açık olduğu bildirilmektedir. Mine sement birleşimindeki bu farklılılar tek bir dişte görülebildiği gibi aynı hastanın farklı dişlerinde de görülebilmektedir.

Dentin hassasiyeti görülen hastalarda mikroskobik inceleme sonrası dentin tübüllerinin daha fazla sayıda ve daha geniş oldukları görülmüştür. Dentin hassasiyetinde rol oynayan dentin tübüllerinin çapı genişledikçe hassasiyet oranı artmakta, bununla birlikte ortama açılmış dentin içinde bulunan dentin tübül yoğunluğu da hassasiyet oluşumunda etkili olmaktadır. Bu yapıyı araştıran çalışmalarda dentin hassasiyeti bulunan dişlerde normal dişlere oranla yedi kat daha fazla açık dentin tübülü olduğu ve bu tübüllerin 2 kat daha fazla genişlikte olduğu bildirilmektedir. ${ }^{7,8}$ Bununla birlikte ortama açılmış her dentin yüzeyinde hassasiyet olması gerekmez, hastanın yaşı, fizyolojik ve psikolojik durumu, ağrı eşiği ve pulpaya yakın bölgede tamir dentini oluşması, eksik veya hatalı diş fırçalama, düşük seviyede oral hijyen, periodontal tedaviler, ekzojen ve endojen kaynaklı asit ürünleri, aşırı kuvvetler gibi faktörler dentin hassasiyeti oluşumunu etkileyebilmektedir.

\section{Dentin Hassasiyeti Mekanizması}

Mine ya da dentin dokusu üzerine gelen herhangi bir uyaranın pulpal dokuya iletimi ve dentin hassasiyetini açıklamak üzere üç farklı hipotez öne sürülmüştür. ${ }^{6}$ Bunlar; odontoblastik transdüksiyon teorisi, nöral teori, hidrodinamik teoridir. Odontoblastik transdüksiyon teorisinde odontoblastların dentin tübülleri içerisindeki odontoblastik uzantılarının dentinde reseptör mekanizması olarak çalıştıkları kabul edilmektedir. ${ }^{4,6}$ Ancak günümüzde odontoblastik uzantıların nörotransmitter saldığına dair hiçbir kanıt bulunamamıştır. ${ }^{4}$ Nöral teori ise odontoblastik transdüksiyon teorisinin bir uzantısı olarak kabul edilmektedir. Nöral teoriye göre ısısal, kimyasal veya mekanik uyarıların doğrudan pulpa içerisindeki sinir lifleriyle ilişkide bulunan dentin tübüllerinin içindeki sinir uçlarını uyararak iletimi sağladıkları öne sürülmüştür. ${ }^{4}$ Kök dentininin dış tabakaları içerisinde miyelinsiz sinir liflerinin varlığının gösterilmesi ve bu sinir sonlanmaları alanlarında nörojenik polipeptitlerin varlığı bu teoriyi desteklemektedir. ${ }^{9,10}$ Açık sinir uçlarına uygulanan lokal anestezik maddeler sinirlerin ağrı iletimini durdururken açık dentin yüzeyine uygulandıklarında ağrı oluşumu engellenememektedir. Bu nedenle dentin hassasiyet mekanizmasının bu teoriye bağlı olamayacağı bildirilmektedir. ${ }^{11}$ Günümüzde geçerliliği devam eden ve araştırmalarda en çok kabul gören teori Hidrodinamik Teori, Brännström ve ark ${ }^{12-14}$ tarafından ileri sürülmüştür. Bu teoriye göre her türlü uyarı dentin tübülleri içerisindeki dentin sıvısının hidrodinamik hareketi ile pulpaya iletilmektedir. Isısal, fiziksel veya ozmotik değişimler dentin sıvısı hacminin değişimine veya hareketine neden olarak pulpadaki basınç reseptörlerini uyarmakta ve bu da sinirler üzerinde impulslar oluşturmaktadır. ${ }^{4}$

\section{Dentin Hassasiyetinin Teşhisi}

Dentin hassasiyetinin ağıı iletişimi anlaşıldıktan sonra dikkat edilmesi gereken bir diğer nokta da, diş ağrısına neden olan birçok durumun (dental patolojinin) dentin hassasiyetiyle karıştırımasıdır. Bu durumlar; çatlak dişlerin varlığı, apseli veya vital olmayan dişler, abrazyon, erozyon, abfraksiyon lezyonları, restorasyon sonrası oluşan hassasiyet, çürük dişler, kırık dişler, kırık restorasyonlar, dişeti enflamasyonu, dişeti çekilmesi, palato-gingival oluk, marjinal sızıntı, dişlerin beyazlatılması sonrası oluşan hassasiyet, diyete bağlı hassasiyet ve kullanılan ilaçlara bağlı oluşan hassasiyetlerdir. ${ }^{15} \mathrm{Bu}$ tip patolojiler kolaylıkla tedavi edilmekle birlikte, yine de gözden kaçırılmaması gereken nokta, dentin hassasiyeti ve çürüklerinin bir arada bulunabilme olasılığı ve bu nedenle teşhiste sıklıkla hata yapılmasıdır. İlgili durumu önlemek için, hastadan iyi bir anamnez alınıp ayrıntılı bir klinik ve radyografik muayenenin yapılması gereklidir.

\section{Dentin Hassasiyetinin Tedavisi}

Dentin hassasiyetinin tedavisinde ilk aşama etyolojik faktörleri belirlemek ve bu faktörleri ortadan kaldırmaktır. Hastanın dişlerini eksik veya hatalı diş fırçalama durumunda dişlerin doğru yöntemle fırçalanması, fırçalamanın uygun sürede ve doğru zamanlama ile yapılması konularında hastalar bilgilendirilmelidir. Eğer dentin hassasiyetine neden olan etyolojik faktör eroziv bir lezyon ise; öncelikle hastanın beslenme alışkanlıklarının düzeltilmesi, tükürüğün dişleri yıkamasındaki yetersizliğinin giderilmesi, fluorürlü veya kalsiyum 
içerikli sakızlar ile fluorlu ağız gargaralarının kullandırılması hekimin öncelikli uygulamaları arasında yer almalıdır. ${ }^{16}$ Ekzojen ve endojen kaynaklı asit ürünleri tüketimi azaltılması tavsiye edilmelidir, Dentin hassasiyetine neden olan etyolojik faktörün abfraksiyon lezyonu olması halinde ise; sentrik veya dinamik oklüzyondaki non-fizyolojik kapanışın selektif möllemeler yapılarak düzeltilmesi, varsa hatalı protezlerin yenilenmesi ve parafonksiyon alışkanlıklarının önlenmesi gerekmektedir. ${ }^{17}$ İkinci aşamada ise hassasiyet giderici ajan uygulamaları düşünülebilir. ${ }^{2}$ Bu konuda çok fazla sayıda tedavi seçeneği bulunmaktadır (Tablo 1). Bu yöntemlerin temel amacl; dentin tübüllerinin tıkanarak SIVI hareketinin bloklanması ve duyu sinirlerinin duyarlıı̆ııın azaltılarak uyarana karşı cevabının değiştirilmesidir. ${ }^{18}$

Tablo 1. Dentin hassasiyeti tedavisinde kullanılan ajanlar

\begin{tabular}{|c|c|}
\hline \multicolumn{2}{|l|}{$\begin{array}{l}\text { 1) Sinirin Duyarsızlaştırılması: } \\
1.1 \text { Potasyum nitrat }\end{array}$} \\
\hline \multicolumn{2}{|l|}{$\begin{array}{l}\text { 2)Anti-enflamatuvar Ajanlar: } \\
\text { 2.1.Kortikosteroidler }\end{array}$} \\
\hline \multicolumn{2}{|c|}{ 3) Dentin Tübüllerinin Tıkanması veya Örtülmesi: } \\
\hline 3.1 Dentin Tübüllerinin Tıkanması & 3.2 Dentin Örtücüler \\
\hline $\begin{array}{l}\text { 3.1.1 İyonlar/Tuzlar: } \\
\checkmark \text { Kalsiyum hidroksit } \\
\checkmark \text { Ferröz oksit } \\
\checkmark \text { Potasyum oksalat } \\
\checkmark \text { Sodyum monofluorofosfat } \\
\checkmark \text { Sodyum florit } \\
\checkmark \text { Sodyum florit -Stannöz florit } \\
\text { Kombinasyonu } \\
\checkmark \text { Stannöz florit } \\
\checkmark \text { Stronsiyum klorid } \\
\checkmark \text { Bioaktif camlar } \\
\text { 3.1.2 Protein Çökelticileri } \\
\checkmark \text { Gluteraldehid } \\
\checkmark \text { Formaldehid } \\
\checkmark \text { Gümüş nitrat } \\
\checkmark \text { Stronsiyum klorid heksahidrat } \\
\checkmark \text { Pro-Argin } \\
\checkmark \text { Bioactive Glass } \\
\text { 3.1.3 Kazein fosfopeptitler } \\
\text { 3.1.4 Parlatmak } \\
\text { (Burnishing) } \\
\text { 3.1.5 Florit iyontoforezi }\end{array}$ & $\begin{array}{ll}\checkmark & \text { Cam iyonomer simanlar } \\
\checkmark & \text { Kompozitler } \\
\checkmark & \text { Rezinler } \\
\checkmark & \text { Vernikler ve jeller } \\
\checkmark & \text { Örtücüler }\end{array}$ \\
\hline \multicolumn{2}{|c|}{ 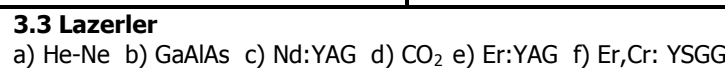 } \\
\hline \multicolumn{2}{|c|}{ 3.4 Periodontal Plastik Cerrahi Uygulamaları } \\
\hline
\end{tabular}

\section{a) Sinirin Duyarsızlaştırılması}

\section{Potasyum Nitrat:}

Hodosh $^{19}, \%$ 1-15'lik konsantrasyonlarda potasyum nitratın topikal uygulamasının dentin hassasiyetinin giderilmesinde etkili olduğunu belirtmekte ve çalışmasında elde edilen etkinliğin oksidasyon veya tübüllerin kristalleştirilmesi ile meydana gelen sinir blokajı şeklinde gerçekleştiği ifade etmektedir. Yüksek miktarlarda uygulanan potasyum iyonlarının ekstraselüler potasyum konsantrasyonunu artırdığı ve böylece sinir membranlarını depolarize ederek sinirlerin ilk başta uyarıması ve bunu ileride aksiyon potansiyeli yayılımında bir blokaj oluşturduğu ve depolarizasyon aktivitelerinin sonucu oluştuğu gösterilmiştir. ${ }^{20}$ Ancak, bu görüşün aksi yönde potasyum klorür, potasyum nitrat ve potasyum sitrat içeren hassasiyet giderici ürünlerin intradental sinirleri inhibe ederek etki ettiklerine dair yeterli kanıtların olmadığını belirten araştırmacılar da bulunmaktadır. ${ }^{21,22}$

\section{b) Antienflamatuar Ajanlar}

Antienflamatuar ajanlardan biri olan kortikositeroidler hassasiyet gidermede kullanılsa da bu ajanların klinik uygulamadaki geçerliliği henüz kanıtlanmamıştır. $^{4}$

c) Dentin Tübüllerini Kapatan ve Tıkayan Ajanlar:

\section{- İyonlar/tuzlar}

\section{Kalsiyum Hidroksit:}

Kalsiyum hidroksitin dentin hassasiyeti tedavisindeki kalsiyum iyonlarıyla protein yapıyı çözmek ve mineralizasyonu arttırarak dentin tübüllerini tıkayarak veya peritübüler dentin oluşumunu stimüle ederek gösterdiği bildirilmiştir. ${ }^{23}$ Kalsiyum hidroksit çabuk etki göstermekle birlikte pek çok uygulama gerekmekte$\operatorname{dir}^{24}$ ve yüksek alkalen $\mathrm{pH}$ seviyesi gingival dokulara toksik etkisi olduğu düşünülmektedir. ${ }^{4}$

\section{Oksalat Bilesikleri}

Oksalat bileşikleri olan potasyum oksalat ve ferrik oksalat dentin hassasiyetinde kullanılan diğer ajanlardır. Dentin yüzeyine uygulandığında dentindeki kalsiyum iyonlarıla reaksiyona girerek dentin tübüllerini tıkayan çözünmeyen kristaller oluştururlar. ${ }^{25}$ Çeşitli çalışmalarda kullanılan \%6'ık ferrik oksalat, $\% 30$ 'luk dipotasyum oksalat ve \%3'ük monohidrojenmonopotasyum gibi oksalat bileşiklerinin hassasiyeti azaltmada etkili olduğu bildirilmektedir. ${ }^{26,27}$ Ayrıca oksalat bileşikleri ile ilgili yapılan güncel sistematik derlemede \%3'luk monohidrojen-monopotasyum oksalat'ın hassasiyeti azalttığını bildirilmiş ancak daha çok çalışma yapılmasına önerilmektedir. ${ }^{28}$ Diğer yandan potasyum oksalatın potansiyel toksisitesi nedeniyle klinik uygulamasında sınırlamalar olduğu belirtilmekte ve gastrik irritasyona neden olduğu için dentin hassasiyetinin tüm ağızda olduğu durumlarda plak ile 
uygulama yapıımasının doğru olmadığı bildirilmektedir. $^{29}$

\section{Florit Bilesikleri}

Florür, ilk kez Lukomsky, 30 tarafindan hassasiyet ajanı olarak öne sürülmüş, Hoyt ve Bibby, ${ }^{31}$ tarafından yapılmış diğer bir çalışmada da bu etki desteklenmiştir. Sodyum florid ve stanoz florid gibi florit bileşiklerin dentin tübüllerinin tıkanmasında ve klinik olarak hassasiyetin azaltılmasında pozitif etkileri olduğu bildirilmektedir. ${ }^{18}$ 1992'de Amerikan Diş Hekimleri Birliği $\% 5$ 'lik potasyum nitrat ve florür içeren macunları kategori I denilen en güvenilir sınıfta tanımlamıştır. Açı̆̆a çıkmış dentin yüzeylerine Sodyum florür (NaF) uygulanması dentin sıvısını kalsiyum ve fosfat iyonlarına doyurarak kalsiyum flüorür kristallerinin çökelti oluşturmasına ve dentin kanallarının mekanik olarak tıkanması nedeniyle de kanal çaplarının daralmasına ve uyarı iletiminin durmasına imkan sağlamaktadır. Birçok klinik çalışmada açığa çıkmış kök yüzeylerinde, florlu diş macunları ve konsantre flor solüsyonlarının dentin hassasiyeti tedavisinde etkili ajanlar olduğu gösterilmiştir. ${ }^{32-34} \mathrm{NaF}$ uygulamasından sonra fluorürün ağız sıvılarıyla hızlıca çözülerek kaybolması nedeniyle topikal uygulamanın sınırlı etkiye sahip olduğu için tek seferde dentin kanallarını tıkamaya yeterli olmadıkları için birkaç defa uygulanmaları gerektiği belirtilmiştir. ${ }^{35}$ Florit cilasının etkili bir şekilde dentin hassasiyetini azalttığı ve bu etkinin 6 ay devam ettiğini bildirmiştir. ${ }^{36}$ Fakat yapılan bir diğer çalışmada NaF'ın cila olarak uygulanması diş yüzeyine tutunma süresinin arttırması açııından alternatif bir yaklaşım olarak kullanılsa da bu etkinin oldukça kısa süreli olduğu belirtilmiştir. ${ }^{37}$

\section{-Protein Çökeltiler:}

\section{Gluteraldehit}

Gluteraldehit dentin sIvısındaki plazma proteinlerinin koagülasyonu ile dentin geçirgenliğini azaltmaktadır. $^{28,38}$ Gluteraldehitin dentin hassasiyeti semptomlarını azaltmada etkin olduğu çeşitli çalışmalarda bildirilmiştir. ${ }^{39-42}$ Gluteraldehitin sitotoksik etkilerinden dolayı özellikle dişeti dokusunun yalıtımının çok iyi yapılması ve hastalara dikkatli bir şekilde uygulanması gerekmektedir.

\section{hassasiyet patı \\ Arginin ve kalsiyum karbonat içerikli}

Dentin hassasiyeti tedavilerinde kullanılan ürünlerin etkinliğinin kısa sürmesi nedeniyle Kleinberg ve ark. ${ }^{43} 2002$ yllında tükürüğün dentin duyarlıı̆ı̆ıı azaltıcı doğal etkisini taklit ederek, tükürükte doğal olarak bulunan bir amino asit olan arginin ile kalsiyum karbonat içeren pro-argin teknolojisini geliştirmişlerdir. $\% 2^{\prime}$ lik potasyum iyonu içeren diş macunu ile $\% 8^{\prime}$ lik arginin kalsiyum karbonat florür içeren diş macununun karşılaştırıldığı 8 haftalık iki farklı çalışmada arginin içeren diş macununun daha üstün olduğu bildirilmektedir. ${ }^{44,45}$ Arginin formülasyon intiva eden diş bakım ürünleri topikal olarak uygulandığında dentin hassasiyetinde hemen rahatlama sağlama avantajına sahiptirler. ${ }^{46}$

\section{Kazein fosfopeptit}

Amorf kalsiyum fosfatın ağız ortamına taşınması için çeşitli araştırmalar sonucunda amorf kalsiyum fosfat (ACP) ile kazein fosfopeptit bileşimi ortaya çıkmıştır. Florit varlığında sinerjik bir etkiye sahiptir. ${ }^{47}$ Güncel çalışmalarda bulgular Kazein Fosfopeptit Amorfoz Kalsiyum Fosfat (CPP-ACP)'nin floridli diş macunundan sonra kullanımını önermektedir. ${ }^{48}$ Karbonat solüsyonundaki ACP kristalize olur ve hidroksiapatit oluşturur. Bu kristaller mikroskobik yüzey defektlerini doldurur, erken çürük defektlerini onarır ve dişleri daha pürüzsüz, kuvvetli ve daha az hassas hale getirirler. ${ }^{48}$ Kalsiyum fosfat dentin tübüllerinin ağzını kapatır ve geçirgenliğini azaltır. ${ }^{49-51}$ Diş hassasiyeti tedavilerinin yanı sıra diş beyazlatma tedavileri sonucunda oluşan hassasiyetlere karşı da kullanılabilmektedir. \%8 arginin, CPP-ACP yada novamin teknolojisi zaman zaman tatmin edici sonuçlar göstermekle birlikte ${ }^{52,53}$ bu materyallerin etkinliğinin 3 aydan daha kısa sürmesi ${ }^{54-56}$ yeni materyal arayışlarına neden olmaktadır.

- Flor iyontoforezi:

1961 yllında geliştirilen elektroforetik olarak çalışan iyontoforetik bir cihaz ${ }^{57}$, sodyum floritle birlikte düşük amperli bir elektrik akımı yardımı ile iyon difüzyonunu arttırma prensibi ile çalışmaktadır. ${ }^{58,59}$ İyontoforez ile dentin tübüllerinde florit iyon penetrasyonu arttırımaktadır. Bu yöntemin klinik olarak araştırıldığı bir çalışmada, NaF ile uygulanan iyontoforez yönteminin diş hassasiyetini1 hafta sonunda $\% 89,3$ oranında azalttığı, sadece sodyum florür uygulanan grupta ise bu azalmanın ancak bir ay sonra \% 23,4 oranında olduğu bildirilmektedir. ${ }^{60}$ Çalışmalar kısa dönem için etkili sonuçlar vermekle birlikte uzun süreli çalışmalara intiyaç bulunmaktadır. ${ }^{61,62}$ 


\section{d) Dentin yüzeyini örten ajanlar}

-Rezinler ve Adezivler:

Yıllardır dentin tübüllerini kapayan rezinlerin ve adezivlerin dentin hassasiyeti tedavisinde etkili olduğu savunulmaktadır. ${ }^{63-65}$ Ancak, bu materyaller başarılı sonuçlar gösterse de, adezivlerin yiyeceklerin ve ağız hijyen uygulamalarının etkisiyle kırılarak ve aşınarak yüzeyden uzaklaşmaları nedeniyle tübüllerin tekrar açığa çıktığı bildirilmektedir. ${ }^{24} \mathrm{Bu}$ sistemlerin etkinliği, dentin kanallarında peritübüler dentin matrisinin duvarına rezin uzantılarının bağlanmasının yetersiz olması nedeniyle sınırlı olmasına rağmen ${ }^{65,66}$ evde uygulanan tedavi yöntemleri ile tedavi edilemeyen durumlarda klinik olarak uygulanabilmektedir. ${ }^{67}$

\section{e) Periodontal Cerrahi}

Genel olarak yumuşak doku greftleri, hassasiyet tedavisinde ilk olarak tercih edilen yöntemlerden biri olmasa da ağız ortamına açılmış kök yüzeylerinin kapatılmasında kullanılan birçok yumuşak doku greft tekniği vardır. Bunlar; laterale kaydırma greftleri, serbest diş eti greftleri, bağ doku greftleri ve koronale çekilen greftlerdir.

\section{f) Restoratif Materyaller}

Dentin hassasiyeti tedavisinde, dentin kanal ağızlarının tamamen örtülerek pulpaya dentin kanalları boyunca ulaşabilen ve ağrı ortaya çıkarabilecek uyaranların iletimleri engellenmek amacıyla invaziv bir çözüm olarak rezin kompozitler ve cam iyonomer simanlar kullanılmaktadır. ${ }^{24}$ Bununla birlikte, restoratif materyallerin kullanılabilmesi için diş dokusunda büyük bir madde kaybı olmalı ya da diğer yöntemlerin, hassasiyeti giderememiş olması gerektiği bildirilmektedir. ${ }^{42,64,68,69}$

\section{g) Lazerler}

Lazerlerle yapılan dentin hassasiyeti tedavisinin etkinliğinin lazer tipi ve parametresine bağlı olarak değişiklik göstermektedir. Dentin hassasiyeti tedavisinde lazerin etki mekanizması farklı 2 mekanizmayla açıklanmaktadır. Bunlardan birincisi lazer ışığının pulpaya ait sinir liflerinin elektrik aktivitesini direkt etkilemesi; ikinci mekanizma ise dentinin tübüler yapısında bir erime sağlanarak dentin kanallarında tıkanmanın sağlanmasıdır. ${ }^{70}$

Dentin hipersensitivitesi için kullanılan lazerler düşük enerjili ve orta enerjili lazerler olmak üzere iki grupta incelenebilir. Düşük enerjili lazerlerden HeliumNeon (He-Ne) lazer, sinirdeki C-fiber afferentleri etkilemez ${ }^{71}$ ama elektrik aktivitesini iletir. ${ }^{72}$ Benzer şekilde
Gallium-Aluminum-Arsenide (GaAlAs) (Diyod/ Semikondüktör) $904 \mathrm{~nm}$ oluşan analjezik etkinin mekanizması tamam olarak bilinmemesine rağmen ${ }^{73}$, sinirdeki C-fiber ${ }^{74}$ afferentleri bloklayarak sinir geçişini baskılaması sonucu analjezi yaratarak dişteki has- sasiyeti engelleyebilmektedir. Orta enerjili lazerler Neodymium: Yttrium-Aluminium-Garnet (Nd:YAG), carbon dioxide $\left(\mathrm{CO}_{2}\right)$, Erbium-Doped Yttrium Aluminum Garnet (Er:YAG) ve Erbium, Chromium: YttriumscandiumGallium- Garnet (Er,Cr: YSGG) lazerler ise dentinin tübüler yapısında bir erime sağlanarak dentin kanallarında tıkanma ve daralma sağlamaktadırlar. ${ }^{75}$ Sadece Nd:YAG $1064 \mathrm{~nm}$ dalga boyunda muhtemelen A beta ve $C$ fibrileri geçiçi olarak bloklanarak ${ }^{76}$ yada duyusal akson sonunu değiştirerek ${ }^{77}$ analjezik etkiye sahip olabilmektedir.

\section{-Lazerin Hassasiyet Giderici Etkisi}

Klasik tedavi yöntemlerinin yetersizliğinden dolayı, dentin hassasiyeti tedavisinde 1980 'lerin ortasından itibaren lazer kullanımı önerilmiştir. Lazerin sert dokular da kullanılmaya başlanmasından sonra lazer uygulamaları klinisyenler arasında artan bir popülariteye sahip olmuştur. ${ }^{78} \mathrm{Bu}$ konuda ilk çalışmalar Matsumoto ve ark. ${ }^{79}$ ve Gutknecht ve ark. ${ }^{80}$ tarafın- dan Nd:YAG lazerle farklı parametrelerde yapılmıştır $(0.3,0.6$ ve $1.0 \mathrm{~W}$ ). Daha sonra yapılan çalışmaların birçoğunda Nd:YAG ve Er:YAG lazer kullanılmıştır. ${ }^{81,82}$ Uygun parametrelerde uygulandığında, dentin hassasiyetinin giderilmesinde Er;YAG lazerin alternatif bir yöntem olduğu, $3 \mathrm{~Hz}$ 'de $80 \mathrm{mj} /$ pulse'de uygulandığında, hassasiyetin azalttığı ve 6 hafta sonrasına kadar bu iyi durumun aynı seviyede devam ettiği bildirilmektedir. ${ }^{83}$ Ayrıca, Nd: YAG lazeri tek başına ve \%5'lik NaF vernikle olan kombinasyonunun dentin hassasiyetine etkisinin değerlendirildiği çalışmalarda Nd:YAG lazer ve \%5'lik NaF vernik kombinasyonunun dentin kanalı girişlerinin kapanmasında oldukça etkili olduğu bildirilmektedir. ${ }^{84,85}$

Son klinik çalışmalar dentin hassasiyetinde lazer tedavisinin etkinliği konusunda farklı sonuçlar vermektedir. Lazerle tedavi sonrası geniş varyasyonlarda dentin hassasiyetine bağlı ağrıda azalma görülmektedir. Etkinlik oranları GaAlAs lazer için 1 aylık takipte $\% 53.3-\% 94.2^{86,87}, \mathrm{CO}_{2}$ lazer için 3 aylık takipte \%50$\% 94.5$ 88,89, Nd:YAG lazer için \%51.5 - \%100 79, Er:YAG lazer de ise yapılan 6 aylık çalışmada \%38.2\% 47 oranında dentin hassasiyetini azalttı̆̆, Er: YSGG'nin kullanımının ise en az 3 ay süreyle dentin hassasiyetine etkisi olduğu bildirilmektedir. ${ }^{90,91}$ 


\section{SONUÇ}

Sonuç olarak, literatür incelendiğinde klinik çalışmalarda farklı materyaller kullanılarak farklı sonuçlar elde edildiği görülmektedir. Dentin hassasiyeti tedavisinde kullanılan pek çok farklı ajanın hassasiyet semptomlarını 3 ile 6 ay arasında azalttığı bildirilmektedir. Materyallerin etkisinin kalıcı olmaması, araştırmacıları yeni materyal ve teknik arayışına yönlendirmektedir.

\section{KAYNAKLAR}

1. Consensus-based recommendations for the diagnosis and management of dentin hypersensitivity. J Can Dent Assoc 2003;69:221-6.

2. Attar N, Korkmaz $\mathrm{Y}$. Dentin aşırı hassasiyeti. Hacetepe Diş hek Fak Derg 2006;30:83-91.

3. Orchardson R. Clinical measurement of hypersensitive dentine. Int Endod J 1993;26:5-6.

4. Bartold PM. Dentinal hypersensitivity: a review. Aust Dent J 2006;51:212-218; quiz 276.

5. Dababneh RH, Khouri AT, Addy $M$. Dentine hypersensitivity - an enigma? A review of terminology, mechanisms, aetiology and management. $\mathrm{Br}$ Dent J 1999;187:606-611; discussion 603.

6. Dowell P, Addy M. Dentine hypersensitivity--a review. Aetiology, symptoms and theories of pain production. J Clin Periodontol 1983;10:341-50.

7. Garberoglio R, Brännström M. Scanning electron microscopic investigation of human dentinal tubules. Arch Oral Bio 1976;21:355-62.

8. Absi EG, Addy M, Adams D. Dentine hypersensitivity. A study of the patency of dentinal tubules in sensitive and non-sensitive cervical dentine. J Clin Periodontol 1987;14:280-4.

9. Frank RM. Attachment sites between the odontoblast process and the intradentinal nerve fibre. Arch Oral Biol 1968;13:833-4.

10. McGrath PA. The measurement of human pain. Endod Dent Traumatol 1986;2:124-9.

11. Pashley D. Dynamics of the pulpo-dentin complex. Crit Rev Oral Biol Med 1996;7:104-33.

12. Brannstrom M. Sensitivity of dentine. Oral Surg Oral Med Oral Pathol 1966;21:517-26.
13. Brännström M, Garberoglio R. The dentinal tubules and the odontoblast processes a scanning electron microscopic study. Acta Odontol 1972;30:291-311.

14. Brannstrom $M$, Astrom $A$. The hydrodynamics of the dentine; its possible relationship to dentinal pain. Int Dent J 1972;22:219-27.

15. Pashley D, Tay F, Haywood V, Collıns M, Drısko C. Dentin hypersensitivity: Consensus-based recommendations for the diagnosis and management of dentin hypersensitivity. Inside Dent 2008;4:1-35.

16. Hughes JA, West NX, Parker DM, van den Braak $\mathrm{MH}$, Addy $\mathrm{M}$. Effects of $\mathrm{pH}$ and concentration of citric, malic and lactic acids on enamel, in vitro. J Dent 2000;28:147-52.

17. Bamise CT, Olusile AO, Oginni AO. An analysis of the etiological and predisposing factors related to dentin hypersensitivity. J Contemp Dent Pract 2008;9:52-9.

18. Shiau HJ. Dentin hypersensitivity. J Evid Based Dent Prac 2012;12:220-8.

19. Hodosh M. A superior desensitizer--potassium nitrate. J Am Dent Assoc 1974;88:831-2.

20. Markowitz K, Kim S. Hypersensitive teeth. Experimental studies of dentinal desensitizing agents. Dent Clin North Am 1990;34:491-501.

21. Orchardson R, Gillam DG. The efficacy of potassium salts as agents for treating dentin hypersensitivity. J Orofac Pain 2000;14:9-19.

22. Poulsen S, Errboe M, Lescay Mevil Y, Glenny AM. Potassium containing toothpastes for dentine hypersensitivity. Cochrane Database Syst Rev 2006;3.

23. Brannstrom M, Isacsson G, Johnson G. The effect of calcium hydroxide and fluorides on human dentine. Acta Odontol Scand 1976;34:59-67.

24. Ling TY, Gillam DG. The effectiveness of desensitizing agents for the treatment of cervical dentine sensitivity (CDS)-a review. J West Soc Periodontol I Abstr 1996;44:5-12.

25. Greenhill JD, Pashley DH. The effects of desensitizing agents on the hydraulic conductance of human dentin in vitro. J Dent Res 1981;60:68698.

26. Trowbridge HO, Silver DR. A review of current approaches to in-office management of tooth hypersensitivity. Dent Clin North Am 1990;34:56181. 
27. Muzzin KB, Johnson R. Effects of potassium oxalate on dentin hypersensitivity in vivo. J Periodontol 1989;60:151-8.

28. Cunha-Cruz J, Stout JR, Heaton LJ, Wataha JC. Dentin hypersensitivity and oxalates: a systematic review. J Dent Res 2011;90:304-10.

29. Guo C, McMartin KE. The cytotoxicity of oxalate, metabolite of ethylene glycol, is due to calcium oxalate monohydrate formation. Toxicol 2005;208:347-55.

30. Lukomsky EH. Floride therapy for exposed dentin and alveolar atrophy. J Dent Res 1941;20:649-52.

31. Hoyt WH, Bibby BG. Use of Sodium Floride for Desensitizing Dentin. J Am Dent Assoc 1943;30:1372-6.

32. Minkov B, Marmari I, Gedalia I, Garfunkel A. The effectiveness of sodium fluoride treatment with and without iontophoresis on the reduction of hypersensitive dentin. J Periodont 1975;46:246-9.

33. Gedalia I, Brayer L, Kalter N, Richter M, Stabholz A. The effect of fluoride and strontium application on dentin: in vivo and in vitro studies. J Periodontol 1978;49:269-72.

34. Kerns DG, Scheidt MJ, Pashley DH, Horner JA, Strong SL, Van Dyke TE. Dentinal tubule occlusion and root hypersensitivity. J Periodontol 1991;62:421-8.

35.Gaffar A. Treating hypersensitivity with fluoride varnish. Compend Contin Educ Dent 1999;20:2733; quiz 35.

36. Ritter AV, de LDW, Miguez P, Caplan DJ, Swift EJ, Jr. Treating cervical dentin hypersensitivity with fluoride varnish: a randomized clinical study. J Am Dent Assoc 2006;137:1013-20; quiz 1029.

37. Lan $\mathrm{W}-\mathrm{H}$, Liu $\mathrm{H}-\mathrm{C}$, Lin C-P. The combined occluding effect of sodium fluoride varnish and $\mathrm{Nd}$ : YAG laser irradiation on human dentinal tubules. J Endod 1999;25:424-6.

38. Porto IC, Andrade AK, Montes MA. Diagnosis and treatment of dentinal hypersensitivity. J Oral Sci 2009;51:323-32.

39. Smith BA, Ash MM, Jr. Evaluation of a Desensitizing Dentifrice. J Am Dent Assoc 1964;68:639-47.

40. Addy M, Mostafa P. Dentine hypersensitivity. I. Effects produced by the uptake in vitro of metal ions, fluoride and formaldehyde onto dentine. J Oral Rehabil 1988;15:575-85.
41. Malferrari S. Desensitizing effects of Gluma and Gluma 2000 on hypersensitive dentin. J Am Dent Assoc 1993;6:283-6.

42. Lone A, Finger W. Clinical evaluation of the role of glutardialdehyde in a one-bottle adhesive. J Am Dent 2002;15:330-4.

43. Kleinberg I. SensiStat. A new saliva-based composition for simple and effective treatment of dentinal sensitivity pain. Dent Today 2002;21:42-7.

44. Docimo R, Montesani L, Maturo P, Costacurta M, Bartolino $M$, DeVizio $W$, et al. Comparing the efficacy in reducing dentin hypersensitivity of a new toothpaste containing $8.0 \%$ arginine, calcium carbonate, and $1450 \mathrm{ppm}$ fluoride to a commercial sensitive toothpaste containing $2 \%$ potassium ion: An eight-week clinical study in Rome, Italy. J Clin Dent 2009;20:17.

45. Ayad F, Ayad N, Zhang YP, DeVizio W, Cummins $D$, Mateo LR. Comparing the efficacy in reducing dentin hypersensitivity of a new toothpaste containing $8.0 \%$ arginine, calcium carbonate, and $1450 \mathrm{ppm}$ fluoride to a commercial sensitive toothpaste containing $2 \%$ potassium ion: an eightweek clinical study on Canadian adults. J Clin Dent 2009;20:10.

46. Schiff T, Delgado E, Zhang Y, DeVizio W, Cummins $D$, Mateo $L$. The clinical effect of a single direct topical application of a dentifrice containing 8.0\% arginine, calcium carbonate, and $1450 \mathrm{ppm}$ fluoride on dentin hypersensitivity: the use of a cotton swab applicator versus the use of a fingertip. J Clin Dent 2009;20:131.

47. Sudjalim TR, Woods MG, Manton DJ, Reynolds EC. Prevention of demineralization around orthodontic brackets in vitro. Am J Orthod Dentofacial Orthop 2007;131:705 e701-9.

48. Kumar VL, Itthagarun A, King NM. The effect of casein phosphopeptide-amorphous calcium phosphate on remineralization of artificial carieslike lesions: an in vitro study. Aust Dent J 2008;53:34-40.

49. Suge T, Ishikawa K, Kawasaki A, Suzuki K, Matsuo $T$, Noiri $Y$, et al. Calcium phosphate precipitation method for the treatment of dentin hypersensitivity. Am J Dent 2002;15:220-6.

50. Forsback A-P, Areva $S$, Salonen JI. Mineralization of dentin induced by treatment with bioactive glass S53P4 in vitro. Acta Odontol 2004;62:14-20. 
51. Cherng A, Chow L, Takagi S. Reduction in dentin permeability using mildly supersaturated calcium phosphate solutions. Arch Oral Biol 2004;49:91-8.

52. Que K, Fu Y, Lin L, Hu D, Zhang YP, Panagakos $\mathrm{FS}$, et al. Dentin hypersensitivity reduction of a new toothpaste containing $8.0 \%$ arginine and 1450 ppm fluoride: an 8-week clinical study on Chinese adults. Am J Dent 2010;23:28A-35A.

53. Sharma N, Roy S, Kakar A, Greenspan DC, Scott R. A clinical study comparing oral formulations containing $7.5 \%$ calcium sodium phosphosilicate (NovaMin), 5\% potassium nitrate, and $0.4 \%$ stannous fluoride for the management of dentin hypersensitivity. J Clin Dent 2009;21:88-92.

54. He T, Chang J, Cheng R, Li X, Sun L, Biesbrock AR. Clinical evaluation of the fast onset and sustained sensitivity relief of a $0.454 \%$ stannous fluoride dentifrice compared to an $8.0 \%$ argininecalcium carbonate-sodium monofluorophosphate dentifrice. Am J Dent 2011;24:336-40.

55. Kakar A, Kakar K, Sreenivasan P, DeVizio W, Kohli R. Comparison of the clinical efficacy of a new dentifrice containing $8.0 \%$ arginine, calcium carbonate, and $1000 \mathrm{ppm}$ fluoride to a commercially available sensitive toothpaste containing $2 \%$ potassium ion on dentin hypersensitivity: a randomized clinical trial. J Clin Dent 2011;23:40-7.

56. Salian S, Thakur S, Kulkarni S, LaTorre G. A randomized controlled clinical study evaluating the efficacy of two desensitizing dentifrices. J Clin Dent 2009;21:82-7.

57. Manning M. A new approach to desensitization of cervical dentin. Dent Surv 1961;37:731-4.

58. McFall WT. A review of the active agents available for treatment of dentinal hypersensitivity. Dent Traumatol 1986;2:141-9.

59. Brahmbhatt N, Bhavsar N, Sahayata V, Acharya A, Kshatriya P. A double blind controlled trial comparing three treatment modalities for dentin hypersensitivity. Med Oral Patol Oral Cir Bucal 2012;17:483-90.

60. Tezel A, Orbak R, Çanakçı V. Periodontal Tedaviler Sonucu Oluşan Dentin Hassasiyetinin Tedavisi. Atatürk Üni Diş Hek Fak Derg 2001;11:40-4
61. Berman LH. Dentinal sensation and hypersensitivity: a review of mechanisms and treatment alternatives. J Periodontol 1985;56:21622.

62. Gillam DG, Newman HN. Iontophoresis in the treatment of cervical dentinal sensitivity-a review. J West Soc Periodontol Abstr 1990;38:129-33.

63. Johnson G. Effects of various conditioners and cleaning agents on prepared dentin surfaces: a scanning electron microscopic investigation. J Prosth Dent 1974;31:422-30.

64. Ferrari M, Cagidiaco MC, Kugel G, Davidson C. Clinical evaluation of a one-bottle bonding system for desensitizing exposed roots. Am J Dent 1999;12:243-9.

65. Swift Jr E, May Jr K, Mitchell S. Clinical evaluation of Prime \& Bond 2.1 for treating cervical dentin hypersensitivity. Am J Dent 2001;14:13-6.

66. Gillam DG, Mordan NJ, Newman HN. The Dentin Disc surface: a plausible model for dentin physiology and dentin sensitivity evaluation. Adv Dent Res 1997;11:487-501.

67. Pol DG, Jonnala J, Chute M, Gunjikar T, Pol SD. Current Strategy in the Management of Dentinal Hypersensitivity. J Ind Dent Assoc 2011;5:746.

68. Prati C, Cervellati F, Sanasi V, Montebugnoli L. Treatment of cervical dentin hypersensitivity with resin adhesives: 4-week evaluation. Am J Dent 2001;14:378-82.

69. Powell LV, Gordon GE, Johnson GH. Sensitivity restored of Class $\mathrm{V}$ abrasion/erosion lesions. J Am Dent Assoc 1990;121:694-6.

70. Addy M, Edgar WM, Embery G, Orchardson R. Tooth wear and sensitivity: Clinical advances in restorative dentistry: CRC Press, 2000.

71. Jarvis D, MacIver MB, Tanelian DL. Electrophysiologic recording and thermodynamic modeling demonstrate that helium-neon laser irradiation does not affect peripheral A delta- or Cfiber nociceptors. Pain 1990;43:235-42.

72. Rochkind S, Nissan M, Razon N, Schwartz M, Bartal A. Electrophysiological effect of HeNe laser on normal and injured sciatic nerve in the rat. Acta Neurochir (Wien) 1986;83:125-30.

73. Mezawa S, Iwata K, Naito K, Kamogawa H. The possible analgesic effect of soft-laser irradiation on heat nociceptors in the cat tongue. Arch Oral Biol 1988;33:693-4.

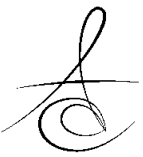


74. Wakabayashi H, Hamba M, Matsumoto K, Tachibana $\mathrm{H}$. Effect of irradiation by semiconductor laser on responses evoked in trigeminal caudal neurons by tooth pulp stimulation. LaserS Surg Med 1993;13:605-10.

75. Matsumoto K, Kimura Y. Laser Therapy of Dentin Hypersensitivity. J Oral Laser Appl 2007;7.

76. Orchardson R, Peacock JM, Whitters CJ. Effect of pulsed Nd:YAG laser radiation on action potential conduction in isolated mammalian spinal nerves. Lasers Surg Med 1997;21:142-8.

77. Myers TD, McDaniel JD. The pulsed Nd:YAG dental laser: review of clinical applications. J Calif Dent Assoc 1991;19:25-30.

78. Cozean C, Arcoria CJ, Pelagalli J, Powell GL. Dentistry for the 21st century? Erbium:YAG laser for teeth. J Am Dent Assoc 1997;128:1080-7.

79. Matsumoto K, Funai $H$, Shirasuka T, Wakabayashi $\mathrm{H}$. Effects of Nd: YAG-laser in treatment of cervical hypersensitive dentine. Japan J Conserv Dent 1985;28:65 by Birang R, Poursamimi J, Gutknecht $\mathrm{N}$, Lampert F, Mir M. Comparative evaluation of the effects of Nd:YAG and Er:YAG laser in dentin hypersensitivity treatment. Lasers Med Sci 2007;22:21-4

80. Gutknecht N, Moritz A, Dercks HW, Lampert F. Treatment of hypersensitive teeth using neodymium:yttrium-aluminum-garnet lasers: a comparison of the use of various settings in an in vivo study. J Clin Laser Med Surg 1997;15:171-4.

81. Kimura $Y$, Wilder-Smith P, Yonaga K, Matsumoto $\mathrm{K}$. Treatment of dentine hypersensitivity by lasers: a review. J Clin Periodontol 2000;27:715-21.

82. Birang R, Kaviani N, Mohammadpour M, Abed AM, Gutknecht N, Mir M. Evaluation of Nd:YAG laser on partial oxygen saturation of pulpal blood in anterior hypersensitive teeth. Lasers Med Sci 2008;23:291-4.

83. Schwarz F, Arweiler N, Georg T, Reich E. Desensitizing effects of an Er:YAG laser on hypersensitive dentine. J Clin Periodontol 2002;29:211-5.

84. Kumar NG, Mehta DS. Short-term assessment of the Nd:YAG laser with and without sodium fluoride varnish in the treatment of dentin hypersensitivitya clinical and scanning electron microscopy study. J Periodontol 2005;76:1140-7.

85. Hsu P-J, Chen J-H, Chuang F-H, Roan R-T. The
Combined Occluding Effects of Fluoride-Containing Dentin Desensitizer and Nd-yag Laser Irradiation on Human Dentinal Tubules: an In Vitro Study. The Kaohsiung J Med Sci 2006;22:24-9.

86. Corona S, Do Nascimento T, Catirse A, Lizarelli R, Dinelli W, Palma-DIBB R. Clinical evaluation of lowlevel laser therapy and fluoride varnish for treating cervical dentinal hypersensitivity. J Oral Rehabil 2003;30:1183-9.

87. Tengrungsun T, Sangkla W. Comparative study in desensitizing efficacy using the GaAlAs laser and dentin bonding agent. J Dent 2008;36:392-5.

88. Zhang $C$, Matsumoto $K$, Kimura $Y$, Harashima T, Takeda $\mathrm{FH}$, Zhou $\mathrm{H}$. Effects of $\mathrm{CO}_{2}$ laser in treatment of cervical dentinal hypersensitivity. J Endod 1998;24:595-7.

89. Moritz A, Schoop U, Goharkhay K, Aoid M, Reichenbach $P$, Lothaller $M A$, et al. Long-term effects of $\mathrm{CO}_{2}$ laser irradiation on treatment of hypersensitive dental necks: results of an in Vivo study. J Clin Laser Med Surg 1998;16:211-5.

90. Yilmaz HG, Cengiz $E$, Kurtulmus Yilmaz $S$, Leblebicioglu B. Effectiveness of Er, Cr: YSGG laser on dentine hypersensitivity: a controlled clinical trial. J Clin Periodontol 2011;38:341-6.

91. Yilmaz HG, Kurtulmus-Yilmaz S, Cengiz E, Bayindir $H$, Aykac Y. Clinical evaluation of Er, Cr: YSGG and GaAlAs laser therapy for treating dentine hypersensitivity: A randomized controlled clinical trial. J Dent 2011;39:249-54.
Yazışma Adresi
Dr. Samet TOSUN
Gaziantep Üniversitesi
Diş Hekimliği Fakültesi
Endodonti Anabilim Dalı
Gaziantep/ TÜRKIYYE
e-mail: samettosun06@gmail.com 